US Army Corps

of Engineers ${ }_{\circledast}$

Engineer Research and

Development Center

\title{
ERDG
}

\section{USACE-ERDC Coastal System Resilience Research}

Katherine F. Touzinsky and Julie D. Rosati

December 2018 
The U.S. Army Engineer Research and Development Center (ERDC) solves the nation's toughest engineering and environmental challenges. ERDC develops innovative solutions in civil and military engineering, geospatial sciences, water resources, and environmental sciences for the Army, the Department of Defense, civilian agencies, and our nation's public good. Find out more at www.erdc.usace.army.mil.

To search for other technical reports published by ERDC, visit the ERDC online library at http://acwc.sdp.sirsi.net/client/default. 


\title{
USACE-ERDC Coastal System Resilience Research
}

\author{
Katherine F. Touzinsky and Julie D. Rosati \\ Coastal and Hydraulics Laboratory \\ U.S. Army Engineer Research and Development Center \\ 3909 Halls Ferry Road \\ Vicksburg, MS 39180-6199
}

Final report

Approved for public release; distribution is unlimited.

Prepared for U.S. Army Corps of Engineers

Washington, DC 20314-1000

Under Project No. 462579, “Navigation Systems Resilience” 


\section{Abstract}

Coastal systems are complex and diverse landscapes that provide significant navigation, flood risk management, and ecosystem services to communities. However, they are influenced by episodic and long-term change from environmental and human-related constraints and hazards. The Coastal System Resilience (CSR) initiative integrates three separate but parallel research, development, and technology (RD\&T) programs (Environmental Restoration, Navigation, and Flood Risk Management) within the U.S. Army Engineer Research and Development Center to address resiliency of this dynamic region. The initiative utilizes new and existing science and engineering to define metrics and to create tools to quantify coastal system resilience of existing and proposed civil works activities. This Special Report describes the motivation and vision for coastal resilience research that was initiated in Fiscal Year 2016 under the CSR RD\&T programs and provides a summary of work to date.

DISCLAIMER: The contents of this report are not to be used for advertising, publication, or promotional purposes. Citation of trade names does not constitute an official endorsement or approval of the use of such commercial products. All product names and trademarks cited are the property of their respective owners. The findings of this report are not to be construed as an official Department of the Army position unless so designated by other authorized documents. 


\section{Contents}

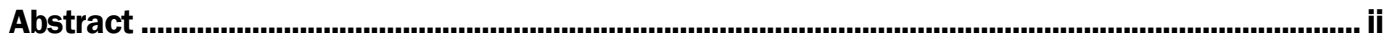

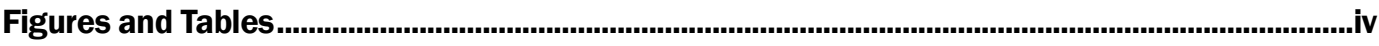

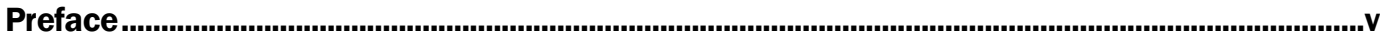

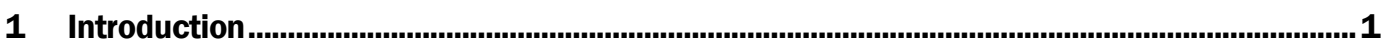

Background: Resilience across the nation ............................................................. 1

Objective: Quantifying resilience ................................................................................ 2

Approach: The Coastal System Resilience (CSR) program................................................ 4

2 Research Summary ............................................................................................................... 8

Research supporting the component and project scales ................................................ 8

Research supporting the multiple-project and community scales ................................... 8

Research supporting the regional and national scales ...................................................... 9

Supporting collaborative research via academia ....................................................... 10

3 Conclusion ..............................................................................................................................15

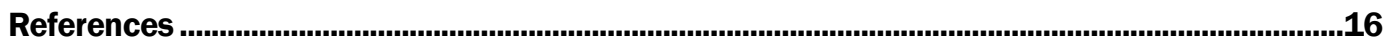

Appendix A: Research Supporting the Component and Project Scales.........................................17

Appendix B: Research Supporting the Multi-Project and Community Scales ..............................24

Appendix C: Research Supporting the Regional and National Scales.............................................29

\section{Report Documentation Page}




\section{Figures}

Figure 1. Coastal systems include infrastructure that supports navigation, the environment, and communities.

Figure 2. The resilience cycle.

Figure 3. The NACCS identified areas highly vulnerable to coastal storms and flooding experienced during Hurricane Sandy (left, purple). The pop-out figure is of the restoration of one of those areas at Rockaway Beach, NY.

Figure 4. The CSR program organization.

Figure 5. Twelve CSR research projects that were funded in FY16. These projects are organized by applicable spatial scale and resilience step. Grey boxes indicate possible areas of future research, which can be addressed through supporting collaborative research (page 13).

Figure 6. Field measurements being taken at Bogue Banks, NC, in October 2016

Figure 7. The study site (highlighted in pink) of the University of North Carolina study on modeling dune growth and the Oregon State University study on simulating dune evolution

Figure 8. The Wind tunnel designed and constructed by the University of Pennsylvania is located in Ocean County Boathouse, Waretown, NJ. .13

Figure 9. Damages resulting from an overtopped beach berm in Kitty Hawk, NC. 


\section{Preface}

This study was conducted for the U.S. Army Corps of Engineers Headquarters (USACE-HQ) under the Navigation Systems Research Program, Project No. 462579; "Navigation Systems Resilience." The Program Manager was Mr. Charles E. Wiggins (CEERD-HT).

The work was performed by the Coastal Processes Branch of the Flood and Storm Protection Division (CEERD-HF), U.S. Army Engineer Research and Development Center, Coastal and Hydraulics Laboratory (ERDCCHL). At the time of publication of this report, Ms. Ashley Frey was Chief, CEERD-HF-C; Dr. Cary Talbot was Chief, CEERD-HF; and Mr. W. Jeff Lillycrop, CEERD-HT, was the ERDC Technical Director for Civil Works and Navigation Research, Development and Technology Transfer (RD\&T) portfolio. The Acting Director of ERDC-CHL was Mr. Jeffrey R. Eckstein, and the Acting Deputy Director of ERDC-CHL was Mr. John T. Tucker.

The Commander of ERDC was COL Ivan P. Beckman, and the Director of ERDC was Dr. David W. Pittman. 


\section{Introduction}

\section{Background: Resilience across the nation}

The purpose of this document is to provide a summary of research conducted by the U.S. Army Engineer Research and Development Center (ERDC), Coastal Systems Resilience (CSR) initiative under three ERDC Research, Development, and Technology Programs: Environmental Restoration, Navigation, and Flood Risk Management. In the wake of natural disasters like Hurricanes Katrina and Sandy, numerous federal studies ${ }^{1}$ have emphasized the need for increasing coastal resilience to limit damages during future events. The ERDC has leveraged ongoing work with many federal, non-federal, local, academic, and community organizations to better define needs, collaborate on ongoing research demonstrations and advancements, develop metrics and tools, and transfer knowledge to other practitioners and the public.

ERDC scientists and partners have been active in advancing the application of resilience concepts across the nation for many types of coastal infrastructure such as wetlands, beach and dune systems, navigation structures, and communities (Figure 1). Several studies have reported on the present state of knowledge regarding coastal resilience assessment frameworks among U.S. federal agencies, academia, and industry. These studies concluded that frameworks in practice generally focus on two evaluation categories: (1) community or local selfassessment/expert-guided analyses, so-called bottom-up assessments; and (2) regional or national-level, top-down frameworks that rely on aggregated federal datasets. Both methods are limited by their scope. Bottom-up assessments are often limited to only local or regional issues, and top-down frameworks often oversimplify a complicated system (Knight and Link 2015). To accurately assess resilience on a larger-thanlocal scale, a balance must be struck between bottom-up and top-down assessments (Larkin et al. 2015). In addition, there are gaps in the

\footnotetext{
${ }^{1}$ For example, USACE: Interagency Performance Evaluation Taskforce (IPET), Mississippi Coastal Improvement Program (MsCIP), and North Atlantic Coast Comprehensive Study (NACCS); Department of Interior: Hurricane Sandy Mitigation and Resilience Program's Ecological System and Infrastructure Resilience; The Nature Conservancy: Coastal Resilience Network; Nearshore Processes R\&D Community (2015); and others
} 
quantitative application of the concepts of resilience to coastal systems. This research initiative will assimilate new data, metrics, tools, and methodologies to provide decision-support and project planning for U.S. Army Corps of Engineers (USACE) engineers, project managers, and other partners in their efforts to understand coastal systems resilience.

Figure 1. Coastal systems include infrastructure that supports navigation, the environment, and communities.

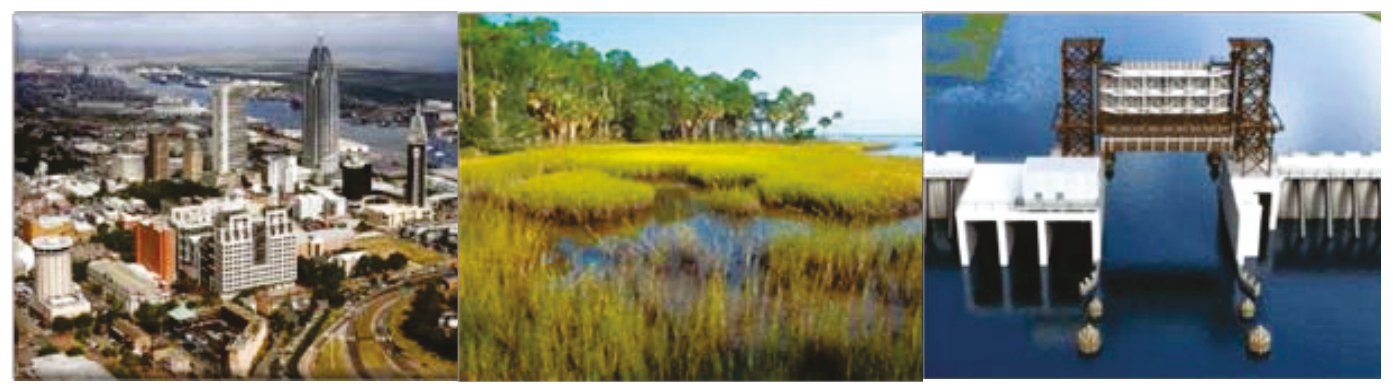

\section{Objective: Quantifying resilience}

Resilience is defined as the capacity to be prepared, withstand or absorb damages, rapidly recover, and adapt to long-term changes (Figure 2), and is a desirable characteristic for natural, nature-based, and built infrastructure and the community systems that encompass these features. Numerous evaluation methodologies focus on fostering community resilience. However, a disparity exists within published literature between work that guides building community resiliency and that which actually quantifies it.

Figure 2. The resilience cycle.

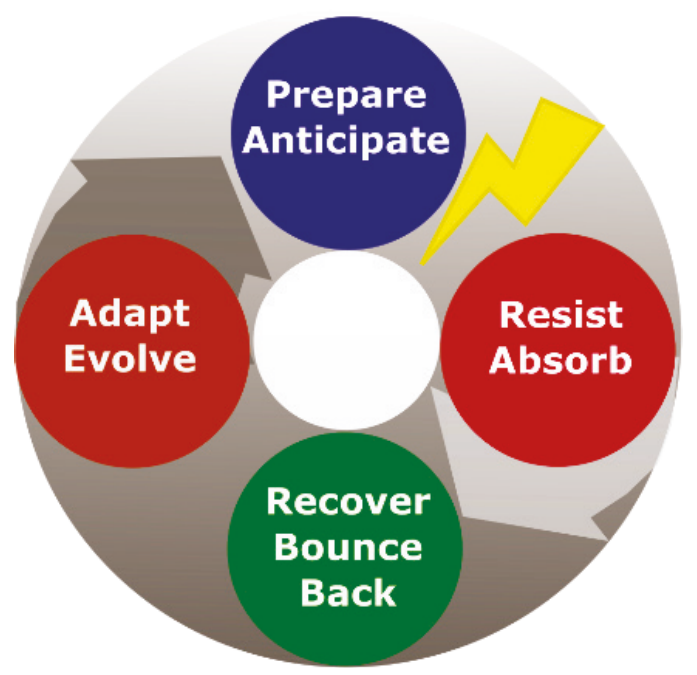


A 2015 review of community resilience research found that of a total of 675 articles that referred to community resilience, only 17 had developed methodologies for measurement. Those 17 methods were predominantly qualitative (Ostadtaghizadeh et al. 2015). Qualitative methods are crucial steps in establishing coastal community resilience. They initiate conversation among a diverse group of stakeholders, they can highlight the interdependencies that occur during the stages of a disaster (i.e., preparation, response, and recovery), and they increase overall education about the serious risks that coastal communities face. In addition, qualitative methods can be utilized to understand the dynamics of a system at any spatial and temporal scale disrupted by a range of occurrences from a quick evaluation to in-depth expert analysis. For this reason, qualitative methods are useful in identifying hot spots or extremely vulnerable areas that need particular attention. For the USACE, qualitative approaches can be helpful in implementing restoration projects immediately after a disaster or identifying future vulnerability. For example, the North Atlantic Coast Comprehensive Study (NACCS) (USACE 2015) conducted following Hurricane Sandy proposed the Coastal Storm Risk Management Framework, which identifies areas of high vulnerability so that information can be used to identify solutions (Figure 3).

Qualitative analysis is useful for many applications. However, for USACE engineers and decision makers to design, construct, and operate more resilient projects and programs, they need information about how their project or program functions within the coastal system before, during, and after a disturbance. To address these specific needs, USACE districts require methods to quantify coastal system resilience that account for the surrounding community and ecosystem functions. These methods also must be flexible enough to quantify performance, failure, and recovery for at least three key USACE mission areas: storm damage reduction, environmental restoration, and navigation. The CSR initiative is addressing both quantitative and qualitative approaches to resilience. 
Figure 3. The NACCS identified areas highly vulnerable to coastal storms and flooding experienced during Hurricane Sandy (left, purple). The pop-out figure is of the restoration of one of those areas at Rockaway Beach, NY.

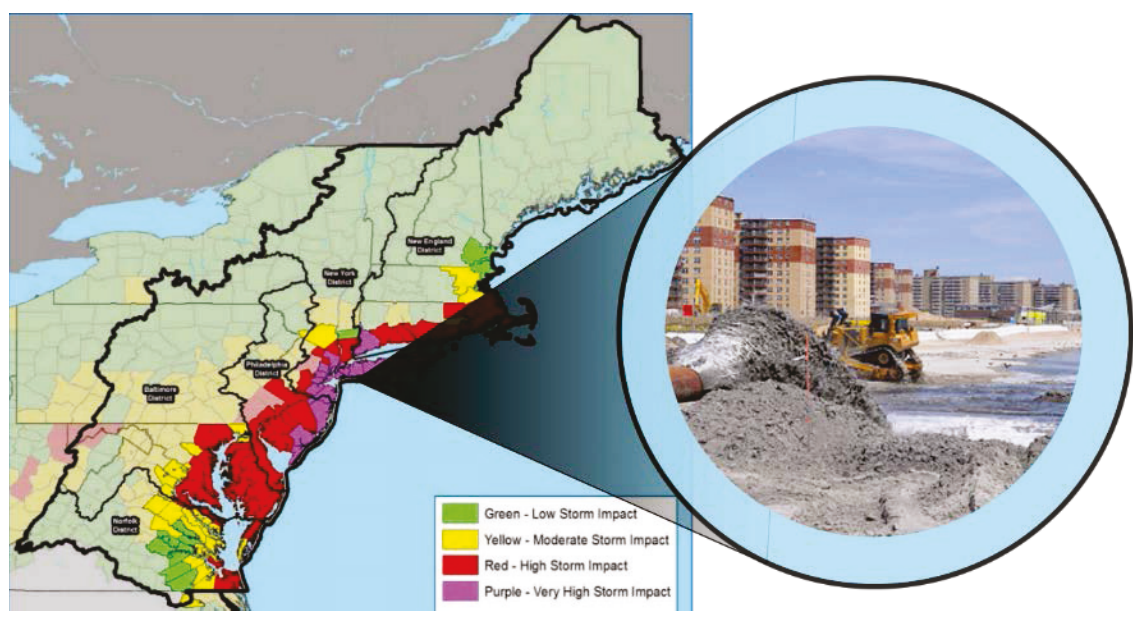

\section{Approach: The Coastal System Resilience (CSR) initiative}

In the spring of 2015, the USACE Civil Works Research and Development (R\&D) Steering Committee approved the implementation of the CSR initiative through research activities supported by three civil works R\&D business lines: Environmental, Navigation, and Flood Risk Management. The CSR initiative integrates all three business lines, districts, partners and stakeholders to contribute to R\&D (including data, functions, indices, demonstrations, and tools) that feed into a Data Integration Framework (DIF) (Spore and Brodie 2016). The DIF will serve as a user-accessible databank to characterize CSR and provide decision-support for increasing project resilience within a graphical user interface (GUI). User needs will then inform the selection of new R\&D projects (Figure 4).

Figure 4. The CSR program organization.

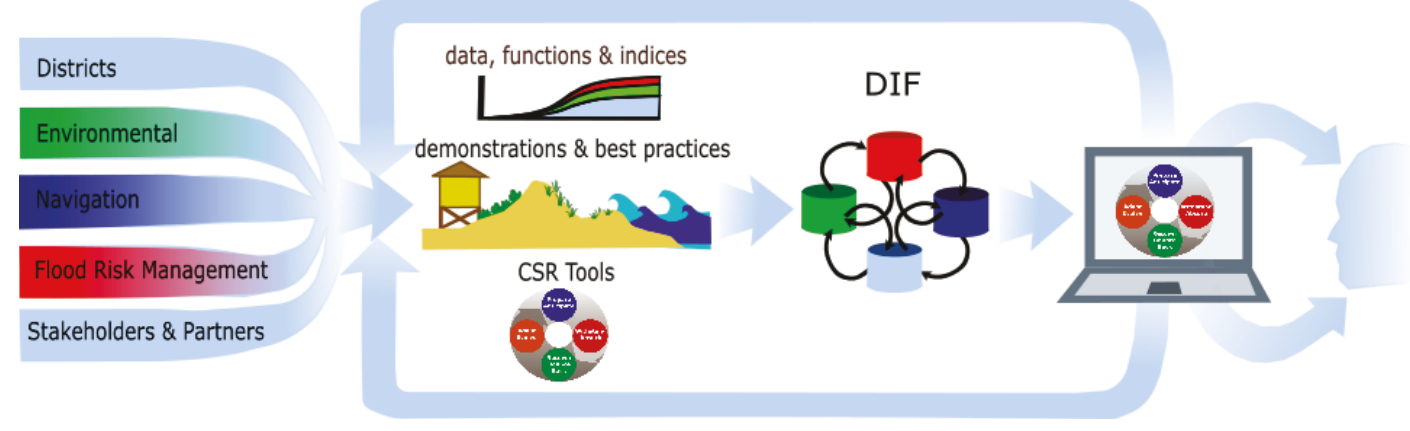

One of the pervasive challenges in developing quantitative methods to analyze resilience is having accurate and informative datasets. The DIF approach will integrate existing datasets that cover a wide range of data 
and metrics from both the USACE and other federal agencies to develop a framework for successful data discovery, access, and utilization. Thoughtful integration of datasets and frameworks is particularly important for the CSR initiative because of the complicated nature of coastal systems, and the need to manage multiple uses and infrastructure types within those systems.

In addition to system dynamics, the CSR initiative will closely track the ability of related research to address the four steps of resilience: Prepare, Resist, Recover, and Adapt.

CSR research is directed towards five goals that are the target of ongoing research:

1. DATA/METRICS: Define data and metrics for measuring coastal system functional health and resilience that are complementary to USACE planning, engineering, and Operations and Maintenance activities now and into the future.

2. FUNCTIONS: Develop analytical and empirical relationships for performance, failure, and recovery of natural, nature-based, and built infrastructure.

3. TOOLS: Leverage existing methods and tools to develop a framework and associated data and operations-informed GUI for assessing project and system-scale coastal resilience.

4. FIELD VALIDATION: Conduct demonstrations to test, validate, and refine tools.

5. TECHNOLOGY TRANSFER: Facilitate the use of new technology and research findings through publications, online tools, workshops, and public outreach.

To assess CSR, a flexible, systems approach is required to appropriately evaluate various time and spatial scales for a range of civil works missions and USACE activities. Within this program, six spatial scales have been identified that are pertinent to the USACE mission: the component, project, multiple project, community, regional, and national scales. These scales aid in the selection of new research to ensure that the entire coastal system is adequately addressed. Twelve CSR research projects were initiated in Fiscal Year (FY) 16 and are shown in Figure 5 as a function of their applicable spatial scale and the resilience step they address. Figure 5 attempts to map all CSR projects and their level of application (for 
example, researching the ability to prepare and adapt at the multipleproject scale) so that future research can be selected to fill identified gaps. This future research may include conducting demonstration studies; developing, testing, and validating methodologies for assessing resilience; refining guidance, and transferring technology. Specific information on these CSR research projects and their respective scales is found in the following section. 
Figure 5. Twelve CSR research projects that were funded in FY16. These projects are organized by applicable spatial scale and resilience step. Grey boxes indicate possible areas of future research, which can be addressed through supporting collaborative research (page 13).
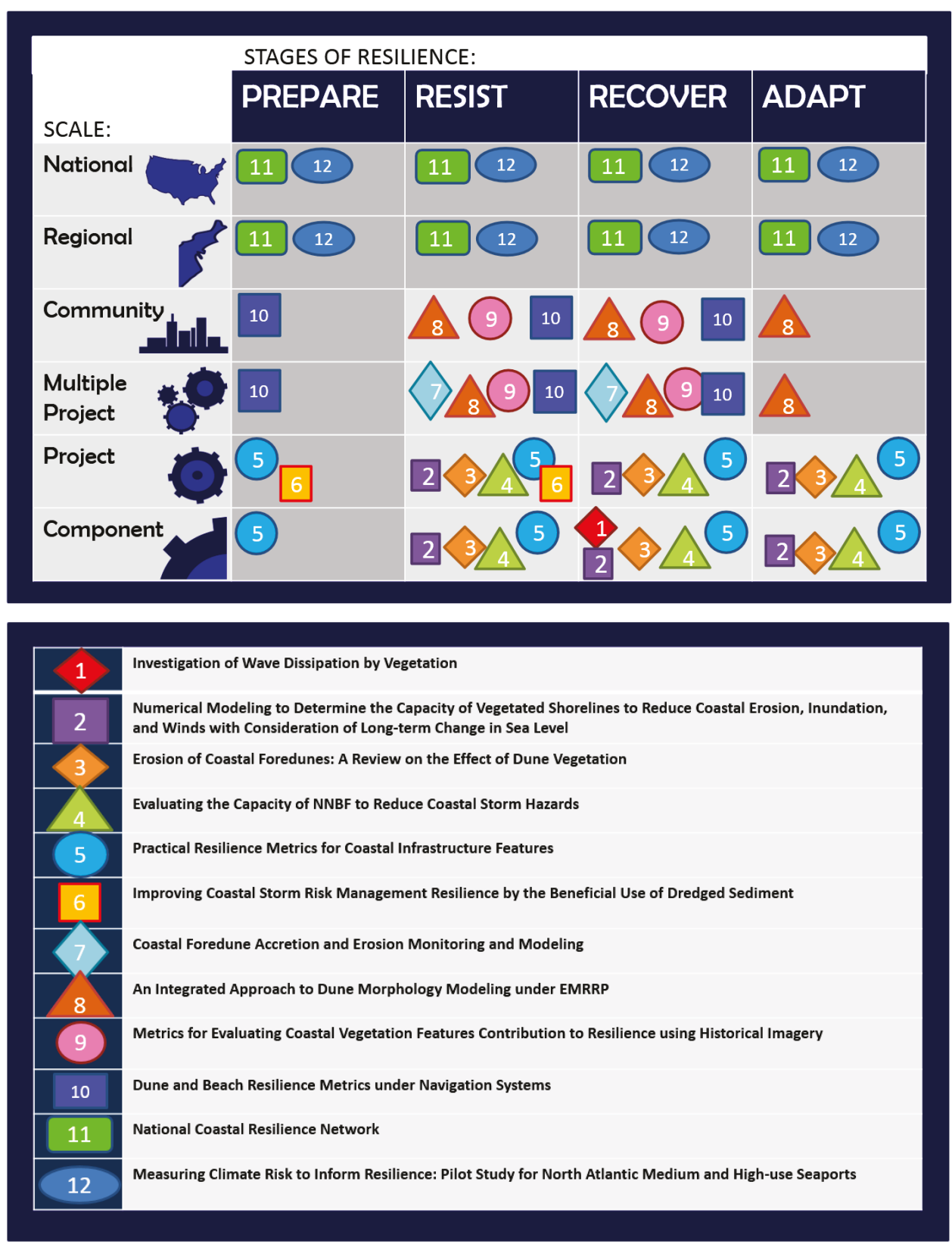


\section{Research Summary}

\section{Research supporting the component and project scales}

The 12 selected research projects address resilience at multiple scales. The component scale is the lowest level of analysis and focuses on a specific aspect of a coastal system. This scale is addressed by a project entitled "Investigation of Wave Dissipation by Vegetation" (Appendix A-1). This research is designed to improve the understanding of the ability of vegetation to dissipate wave energy, thereby adding erosional resistance of the natural feature and the area it protects. The results will provide critical missing information for future evaluations and will inform the flood risk reduction capabilities of vegetation for USACE projects. The next larger scale is the project scale. Four research efforts combine the component and project scale:

- "Numerical Modeling to Determine the Capacity of Vegetated Shorelines to Reduce Coastal Erosion, Inundation, and Winds with Consideration of Long-term Change in Sea Level" (Appendix A-2)

- "Erosion of Coastal Foredunes: A Review on the Effect of Dune Vegetation" (Appendix A-3)

- "Evaluating the Capacity of Natural and Nature-based Features (NNBF) to Reduce Coastal Storm Hazards" (Appendix A-4)

- "Practical Resilience Metrics for Coastal Infrastructure Features" (Appendix A-5)

These projects will result in research products that can be applied directly to a USACE project or to the interactions of that project and its multiple components. These products are tailored to inform the project planning process, engineering design, and/or the monitoring of the project to assess its ability to increase coastal resilience. Only one research effort addresses the project scale alone, "Improving the Coastal Storm Risk Management Resilience by Beneficial Use of Dredged Material” (Appendix A-6). This work focuses on the ability of NNBF projects created through the placement of dredged sediment to provide flood risk reduction benefits.

\section{Research supporting the multiple-project and community scales}

Multiple-project and community scales have significant overlap because both scales approach USACE projects as a system and consider their 
interactions with a diverse range of influences and stakeholders. USACE projects can vary in size from a single lock gate to a navigation channel to the beaches along an entire stretch of coastline. By combining multiple projects, engineers and planners must consider the functional interactions between projects in a particular area. The research entitled "Coastal Foredune Accretion and Erosion Monitoring and Modeling" (Appendix B-1) addresses the multiple-project scale through investigating the interactions between coastal inlet dredging projects, sand transport, and dune creation. Understanding these interactions could lead to better project planning to provide beach protection from erosion.

Three research efforts combine the multiple-project scale with the community scale. The community scale expands beyond USACE projects to incorporate the unique needs of coastal communities and addresses how USACE project(s) can better provide for those needs. The three research projects are as follows:

- “An Integrated Approach to Dune Morphology Modeling under Ecosystem Management and Restoration Research Program” (EMMRP) Appendix B-2)

- "Metrics for Evaluating Coastal Vegetation Features Contribution to Resilience using Historical Imagery" (Appendix B-3)

- "Dune and Beach Resilience Metrics under Navigation Systems" (Appendix B-4).

\section{Research supporting the regional and national scales}

The final two scales considered in CSR projects are the regional and national scales. The regional scale encompasses a geographical area characterized by similar features that are either physical (climate, drainage basin, habitat area) or anthropogenic (governance, culture, language). The definition of a region can be heavily influenced by the feature in question (e.g., maritime shipping, marsh habitat, low-elevation barrier islands, turtle nesting regulations) but also includes a wide variety of social, economic, environmental, and flood risk management needs that exist within that region. FY16 CSR research included two projects that address both the regional and national scale. The first is a collaborative project that is utilizing an online platform to create a resilience decision-making tool that can be tailored to different communities and regions across the nation. This project is called the "National Coastal Resilience Network" (Appendix C-1). The second project aims to utilize the Northeast region to 
develop metrics and indicators for climate change risk to ports:

"Measuring Climate Risk to Inform Resilience: A Pilot Study for North Atlantic Medium and High-Use Seaports" (Appendix C-2).

As the body of coastal resilience research expands across the nation, these research projects will help tailor the development of new work that is beneficial to USACE planning, engineering, and operations processes as well as to the health of surrounding ecosystems and communities. In the coming years, the CSR program will aim to select research that will fill critical gaps in addressing resilience research at multiple scales and for multiple stages of resilience. Moving ahead in this manner will result in helpful and thorough recommendations for making future decisions about the management and assessment of healthy coastal ecosystems.

\section{Supporting collaborative research via academia}

Coastal resilience research within the USACE is not confined to the three topic areas and projects listed above: (1) component and project scales, (2) multiple-project and community scales, and (3) regional and national scales. Many research programs across the USACE address the intricate components of multiple spatial scales across the resilience-related topics of preparation, resistance, recovery, and adaptation. While the research described herein focuses on projects funded by the three USACE business lines, future work within the CSR initiative will attempt to network within existing research programs to understand both the strengths and gaps within the suite of USACE resilience research activities.

In addition to the research discussed above and shown in Figure 5, academic research was initiated in FY16 through collaboration with the U.S. Geological Survey and American Shore and Beach Preservation Association. A collaborative workshop was held in 2015 (Elko et al. 2016), which included a call for research proposals from academia and partnered coastal managers. As a result of this effort, six research proposals were prioritized and jointly funded to address top needs related to coastal dunes research. By focusing intensely on dunes, the proposals were selected to jointly address understanding major research needs and incorporated a variety of academic research institutions across the country. This research primarily targets the component, project, multiple project, and community levels described in Figure 5. The six dune research institutes and their projects include the following: 
1. Oregon State University - Simulating Dune Evolution on Managed Coastlines: Exploring Policy Options with the Coastal Recovery from Storms Tool

This research is designed to expand the Coastal Recovery from Storms Tool by incorporating hydrodynamic, sediment transport, and biophysical processes. Specifically, the ability to incorporate dune grass removal and the presence of hard engineering structures will be added into the model framework. By increasing the capabilities of this tool, the research team will enable the development of strategies for managing beaches that will promote the evolution of dunes and increase project lifecycles. This expansion will be tested through application at Bogue Banks, NC (Figure 6), a heavily populated barrier island with a history of beach management in response to erosion events.

Figure 6. Field measurements being taken at Bogue Banks, NC, in October 2016.
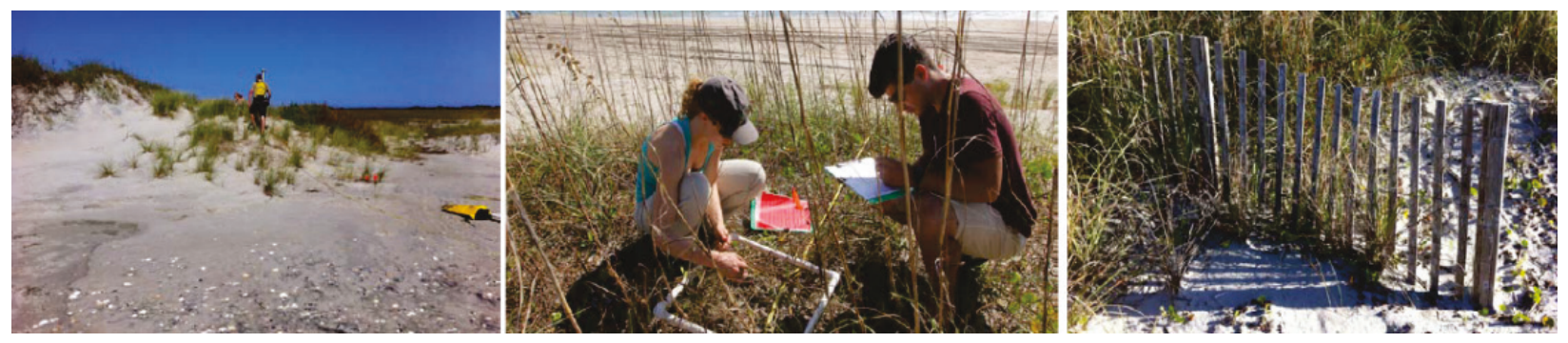

2. University of North Carolina - Modeling Dune Growth on Managed Coasts

The University of North Carolina focused its research proposal to improve models of coastal foredune growth on managed coasts. This will be accomplished through the development of time series observations of topography and vegetation cover using kite-based photogrammetry. This field data will be used to calibrate and test existing models by focusing specifically on 25 kilometers of North Carolina coastal dunes in Bogue Banks, NC, coastline (Figure 7).

The research team has partnered with the Carteret County Shore Protection Office and the National Oceanic and Atmospheric Administration Sentinel Site Partners, and has developed their proposal to complement the Oregon State University proposal described above. 
Figure 7. The study site (highlighted in pink) of the University of North Carolina study on modeling dune growth and the Oregon State University study on simulating dune evolution.

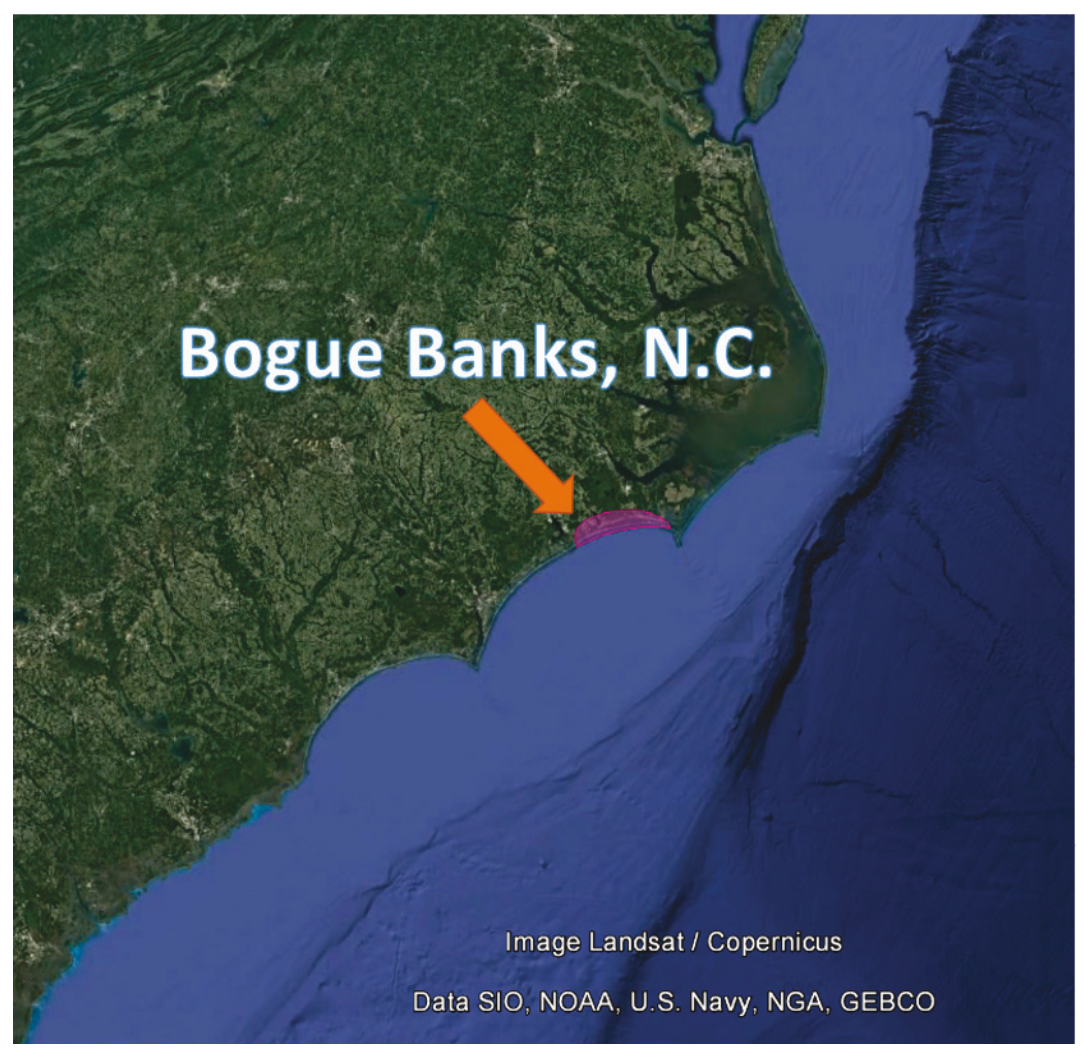

3. University of Pennsylvania - Wind Tunnel Analyses of Vegetation Species Differences in Sand Capture Efficiency and Dune Morphology for Natural and Nature-Based Dune Management

Dune vegetation is a major component of dune growth and longevity. The University of Pennsylvania is constructing a moveable bed wind tunnel (Figure 8) with a capacity of 30 miles per hour winds to serve as a learning facility for testing the sand capture efficiency, retention, and deposition height and angle of selected sand dune vegetation species. The selected species cover a range of habitat specifications, so the findings will be relevant for many natural and manmade coastal dunes across the United States, including the Great Lakes. 
Figure 8. The Wind tunnel designed and constructed by the University of Pennsylvania is located in Ocean County Boathouse, Waretown, NJ.

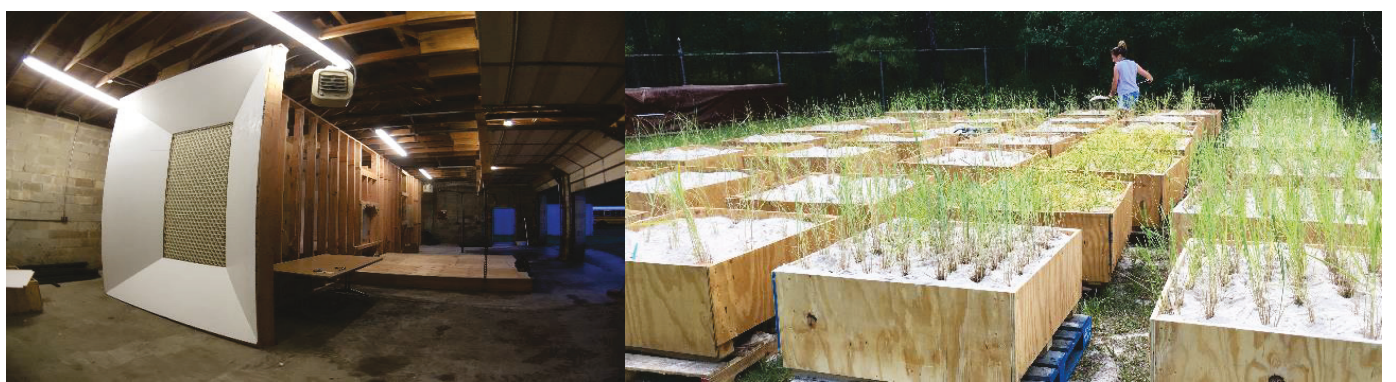

4. North Carolina State University - Dune Design for Overtopping with Constructed Beach Berm

For some beaches, built infrastructure such as roads, homes, and high-rise buildings restricts the space available for constructing dunes for shore protection (Figure 9). The North Carolina State University has designed a research project to better understand how parameters of constructed beaches, specifically the width, berm elevation, and beach slope, affect wave runup on these beaches and dunes so that design guidance can be developed that allows for the natural evolution of dunes and shorelines, even in constricted areas.

Figure 9. Damages resulting from an overtopped beach berm in Kitty Hawk, NC.

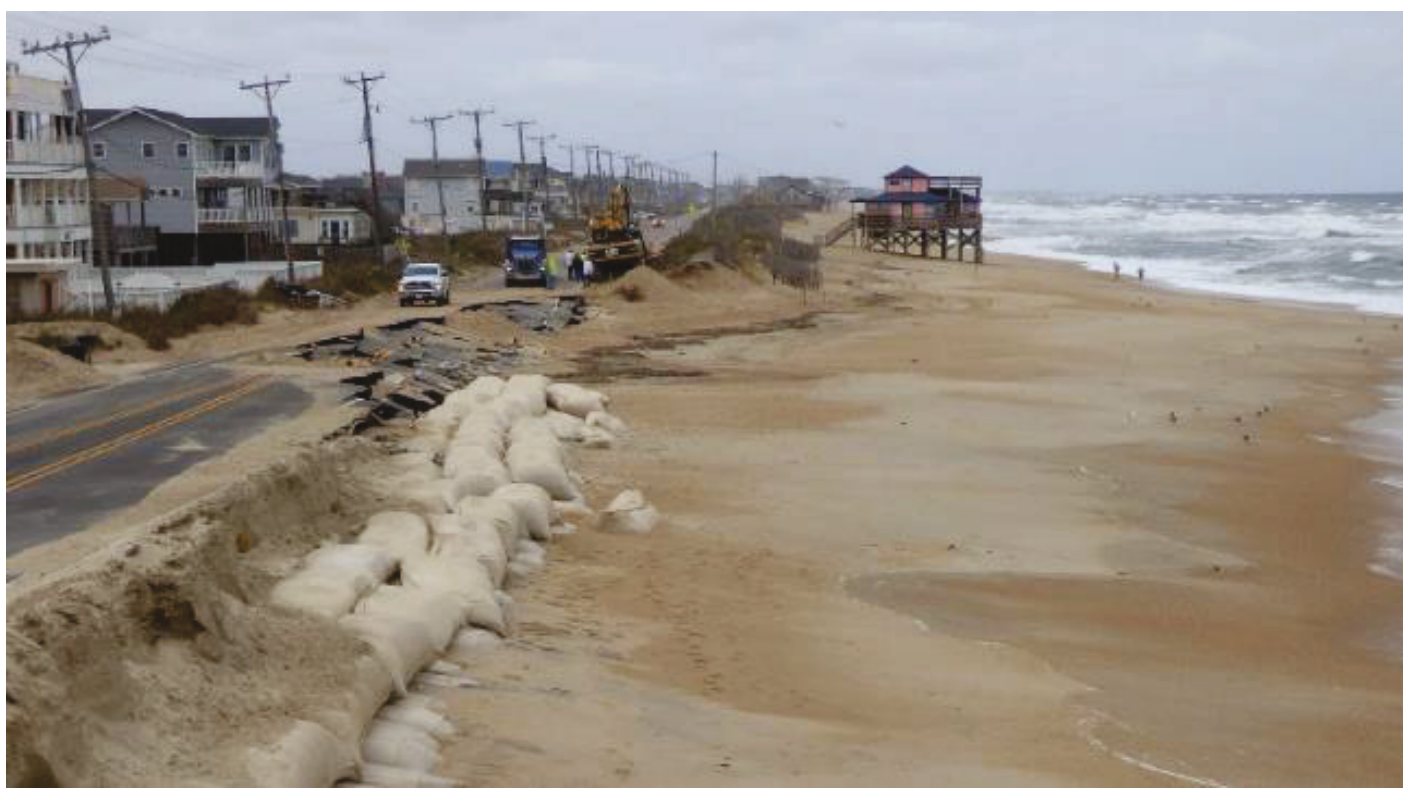


5. Texas A\&M University - Perceptions, Governance, and Stakeholder Relationships along the Texas Coast

The need for dunes is often a subject of debate among coastal communities, and the research proposed by Texas A\&M aims to evaluate perceptions, governance, and stakeholder relationships along the Texas coast as a basis for improving the relevance and quality of technical analysis that result in management decisions. The project will accomplish this goal by creating a stakeholder evaluation database for several communities along the Texas coast including South Padre Island, North Padre Island, and Galveston Island. Future work includes developing a survey for perceptions of risk and resiliency among those community members.

6. University of Alabama - Estimating Coastal Dune Vulnerability to Storm Sequences

The University of Alabama is partnering with coastal managers from Pine Island, NC, to investigate the evolution of dunes subjected to multiple storms to test and refine predictive tools. The methods for executing this project include gathering data for locally representative wind, wave, and water level conditions reported at 3-hour intervals and assessing these data for events that exceed thresholds that indicate potential erosion. Data sources and analysis will involve archive data from multiple contacts. For example, the National Center for Environmental Prediction North American Regional Reanalysis archive will provide wind data for Pine Island, NC. 


\section{Conclusion}

This report was a summation of a CSR research initiative that was funded across three USACE business lines. The research was selected to thoroughly engage with the four concepts of resilience - prepare, resist, recover, and adapt - at six multiple scales. These six scales were identified because of their relevance to the USACE mission: the component, project, multiple project, community, regional, and national. In the future, the ERDC will continue to engage with research topics that are directly related to coastal systems resilience because the coastlines of the United States will face ever-increasing frequencies of stressors and disturbances. The prioritization of these research efforts can be improved by a thorough understanding of the existing knowledge gaps in coastal resilience, the aspects of resilience each project addresses, and the scale at which the project exists. 


\section{References}

Elko, N., K. Brodie, H. Stockdon, K. Nordstrom, C. Houser, K. McKenna, L. Moore, J. Rosati, P. Ruggiero, R. Thuman, and I. Walker. 2016. "Dune Management Challenges on Developed Coasts.” Shore and Beach 84(1): 15-28.

Knight, S. K., and L. E. Link. 2015. "Building Blocks for a National Resilience Assessment." Coastal Hazards Center of Excellence, DHS.

Larkin, S., C. Fox-Lent, D. A. Eisenberg, B. D. Trump, S. Wallace, C. Chadderton, and I. Linkov. 2015. "Benchmarking Agency and Organizational Practices in Resilience and Decision Making." Environment, Systems, and Decisions 55: 185-195.

Ostadtaghizadeh, A., A. Ardalan, D. Paton, H. Jabbari, and H. R. Khankeh. 2015. "Community Disaster Resilience: A Systematic Review on Assessment Models and Tools." PLoS Currents Disasters. http://doi.org/10.1371/currents. dis.f224ef8efbdfcf1d508dd0de4d8210ed

Spore, N. J., and K. Brodie. 2016. Data Integration Framework Data Management Plan - Remote Sensing Dataset. ERDC/CHL SR-16-2. Vicksburg, MS: U.S. Army Engineer Research and Development Center.

U.S. Army Corps of Engineers (USACE). 2015. North Atlantic Coast Comprehensive Study: Resilient Adaptation to Increasing Risk. Main Report. Washington, DC: U.S. Army Corps of Engineers. http://www.nad.usace.army.mil/Portals/40/docs/NACCS/NACCS_main_report.pdf 


\section{Appendix A: Research Supporting the Component and Project Scales}

Investigation of Wave Dissipation by Vegetation ..................................................A-1

Numerical Modeling to Determine the Capacity of Vegetated Shorelines to Reduce Coastal Erosion, Inundation, and Winds with Consideration of Long-term Change in

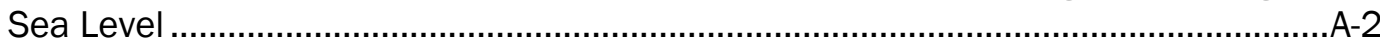

Erosion of Coastal Foredunes: A Review on the Effect of Dune Vegetation ...............A-3

Evaluating the Capacity of Natural and Nature Based Features to Reduce Coastal Storm Hazards .....................................................................................................

Practical Resilience Metrics for Coastal Infrastructure Features .............................A-5

Improving Coastal Storm Risk Management Resilience by the Beneficial Use of

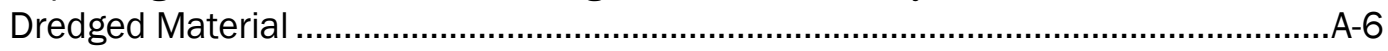




\section{Problem}

The purpose of this work is to use previously collected experimental data in conjunction with data available in the literature to build a comprehensive description of the drag coefficient for wave dissipation by vegetation for improved application in numerical models.

\section{Approach}

The resiliency of coastal communities is important because these areas experience risk of damage from coastal storms, such as hurricanes and extratropicals, as well as increasing population pressures from development and climate change. There is a growing interest in incorporating natural and nature-based features into the project planning process as a complementary approach to traditional structures for reducing flood risk. One of the natural features generally acknowledged to offer some degree of coastal protection is wetlands. The dissipation of wave energy by vegetation has been well documented in both field and laboratory studies. One such extensive laboratory study was conducted as a component of the Wave Dissipation in Vegetation for Coastal Protection Work Unit. To capture these wave energy losses, numerical

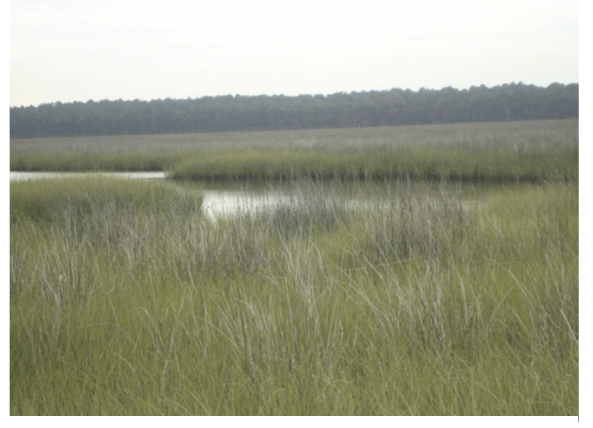

Wetland in coastal Mobile Bay, AL models have historically implemented bottom friction source terms where friction coefficients are assigned according to land cover maps, such as those provided by USGS. However, this approach is problematic because these formulations do not integrate vegetation properties and are unable to account for changes in the flow regime due to spatial variation in plant density, diameter, and degree of plant submergence. Thus, implementing vegetation dissipation formulations that estimate the wave-induced forces along plant stems are of critical importance for accurate modeling of wetland wave dissipation and reducing model uncertainty.

\section{Products}

The Civil Works requirement that this proposal is addressing is the need to provide guidance on model applications. The drag coefficient $\left(\mathrm{CD}_{\mathrm{D}}\right)$ directly influences the degree of wave attenuation in numerical wave models. However, selecting a coefficient value is extremely difficult because parameterizations are species-specific and scattered in various journals and reports. This work will analyze laboratory data for journal publications and will create a guidance document that will be useful to Corps districts for selecting an appropriate $C_{D}$ value. The work plan breaks down into the following tasks:

Task 1. Continued analysis of laboratory data. A series of experiments investigating the transition of submerged to emergent vegetation was completed under the Wave Dissipation in Vegetation for Coastal Protection. These data will be further analyzed to determine the effect of stem submergence ratio on the drag coefficient.

Task 2. Assembling datasets. A comprehensive literature review will be undertaken to amass the drag coefficient parameterizations - current available.

Task 3. Consolidate parameterizations. The parameterizations for $\mathrm{CD}_{\mathrm{D}}$ will be organized and documented in a single guidance document. Methods to generalize the application of the parameterizations will also be investigated.

POC: Mary Bryant, Coastal and Hydraulics Laboratory $(\mathrm{CHL})$

Mary.Bryant@usace.army.mil

Jane Smith, CHL Jane.M.Smith@usace.army.mil 


\section{Numerical Modeling to Determine Capacity of Vege- tated Shorelines to Reduce Coastal Erosion, Inunda- tion, and Winds with Consideration of Long-Term Change in Sea Level}

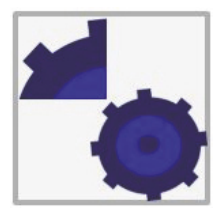

\section{Problem}

The intent of this work is to provide research and evaluation concerning the capacity of vegetated coastal shores, "Living Shorelines," to reduce typical and extreme coastal erosion, inundation, and winds.

\section{Approach}

The USACE is in the process of evaluating the capacity of Natural and Nature-Based Features (NNBF) to reduce risk of coastal storm damage. Vegetated shores are a type of Natural and Nature-based Features (NNBF) believed to reduce chronic erosion and provide some reduction in storm-induced wave erosion, inundation, and wind. Living shorelines are also expected to readily adapt to rising sea level and naturally continue a similar level of risk reduction. However, the capacity of vegetated shorelines in providing these services is largely anecdotal and maintenance requirements are unknown. A quantitative, unbiased study of these features is needed to determine their potential capacity in terms of reducing low-intensity coastal storm damages; defining the threshold coastal storm parameters for which living shorelines become ineffective; determining the conditions under which living shoreline are damaged and will not recover; determining their capacity to keep pace with rising sea level, and the rate of relative sea level change at which they are not able to cope; and applying this knowledge to develop fragility, damage, and recovery profiles for living shorelines.

\section{Products}

Objective 1: Evaluate and provide a brief synopsis of state-of-knowledge on the capacity of living shorelines to reduce coastal erosion, inundation, winds, and keep pace with relative sea level rise.

Objective 2: Calibrate and validate a numerical model for living shoreline response. Demonstrate proofof-validation for representative living shorelines.

Objective 3: Apply the validated model to determine the capacity of living shorelines to reduce low-intensity coastal storm damages. Compare living shoreline risk reduction to that provided by traditional armoring. Determine the threshold storm conditions at which living shorelines are ineffective.

Objective 4: Determine the damage threshold at which living shorelines are unable to naturally recover.

Objective 5: Determine the rate of natural recovery for living shorelines. 


\section{Erosion of Coastal Foredunes: A Review on the Effect of Dune Vegetation}

\section{Problem}

The purpose of this work is to identify the potential roles of vegetation in mitigating coastal dune erosion during storm events.

\section{Approach}

As coastal communities experience greater pressures from ever-expanding populations, sea level rise, and a possible change in storm frequency and/or intensity, sustainable nature-based coastal protection measures are of growing interest. One of these considered features is coastal dunes, which prevent or delay flooding of inland areas by acting as a physical barrier against waves and storm surge (Hanley et al., 2014). Guidance on constructing dune systems considers planting vegetation for promoting dune growth and stabilization against windblown sand transport, but does not consider the potential of vegetation to reduce dune erosion. Knowing whether, and to what degree, vegetation affects the dune response to storms will be invaluable as we pursue efforts to improve coastal resiliency by incorporating natural features into the coastal planning process.

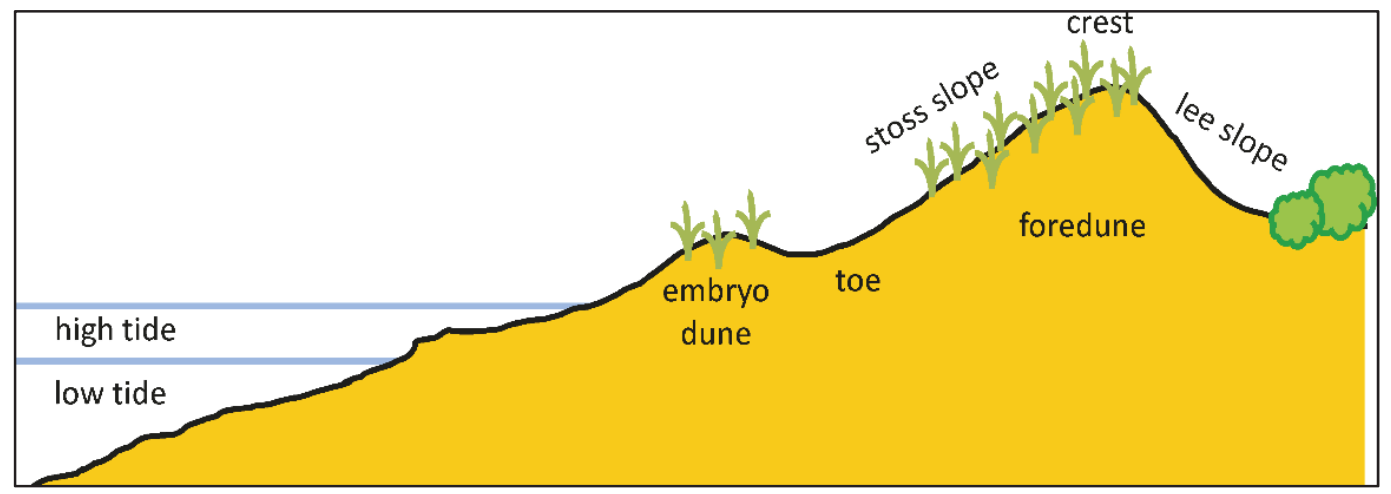

Diagram of a coastal dune system

\section{Products}

This work unit addresses this gap in information through an introduction to coastal dune systems, dune erosion regimes defined by Sallenger (2000), nonwoody species of dune vegetation prevalent to the Atlantic and Gulf of Mexico coasts, a review of research efforts exploring the effects of vegetation on dune erosion, and a future controlled laboratory pilot study to test the effects of vegetation on dune stabilization. While management guidelines for constructing dunes identify vegetation as necessary to trap and accrete sediment, the potential for vegetation to mitigate dune erosion during severe events remains unaddressed due to a paucity of data. This work unit will address those limitations and the products will be utilized to provide further design and engineering guidance for building dune structures for coastal storm risk reduction

POC: Duncan Bryant, Coastal and Hydraulics Laboratory

Duncan.Bryant@usace.army.mil $(\mathrm{CHL})$ 


\section{Problem}

This work will summarize the state of knowledge concerning the capacity of Natural and Nature Based Features (NNBF) to reduce typical and extreme coastal erosion, inundation, and winds.

\section{Approach}

The USACE is in the process of evaluating the capacity of Natural and Nature-Based Features (NNBF) to reduce risk of coastal storm damage. NNBF are believed to reduce chronic erosion and provide some reduction in storm-induced wave erosion, inundation, and wind. NNBF are also expected to readily adapt to rising sea level and naturally continue a similar level of risk reduction. However, the capacity of NNBF in providing these services is largely anecdotal and maintenance requirements are unknown. A summary of the state-of-knowledge concerning how NNBF have performed in past coastal storms, ideally citing studies and post-storm measurements that quantify their capacity to reduce storm waves, winds, and water levels, is needed to concisely define the existing knowledge base. Performance of NNBF in five broad categories is desired: (1) vegetated features (e.g., marshes, living shorelines), submerged and emergent; (2) oyster and coral reefs; (3) beaches and dunes; (4) maritime forests and shrub communities; and (5) barrier islands.

\section{Products}

The results of these technical evaluations of using Natural and Nature-Based Features for coastal storm damage protection will benefit the public by providing additional alternatives to hard engineered structures such as rip rap and pilings. These alternative approaches will potentially provide costs savings and increased environmental benefits. These data will also be used as guidance for coastal property owners, local and state resource agencies and academia.

Objective 1: Evaluate and provide a synopsis of state-of-knowledge on the capacity of NNBF to reduce coastal erosion, inundation, winds, and keep pace with relative sea level rise for vegetated features and oyster \& coral reefs.

Objective 2: Evaluate and provide a synopsis of state-of-knowledge on the capacity of NNBF to reduce coastal erosion, inundation, winds, and keep pace with relative sea level rise for beaches, dunes, maritime forests and shrub communities and barrier islands. 


\section{Practical Resilience Metrics for Coastal Infrastructure Features}

\section{Problem}

This effort is directed towards improving basic understanding of resilience of such complex systems for the development of practical resilience metrics that quantify the capacity to withstand damages, rapidly recover, and adapt to future change. The resilience metrics are based on practical performance measures of coastal infrastructure.

\section{Approach}

The coastal and storm damage reduction, navigation, and environmental missions of the U.S. Army Corps of Engineers (USACE) require consistent, transparent, unbiased, quantitative metrics with which to understand the resiliency of complex coastal systems. Massive savings could be realized by enhancing the resilience of a system, including infrastructure, networks and communities through risk reduction and expeditious recovery. Enhancing system resilience through a combination of infrastructure, flood and storm mitigation, community, and environmental measures has the potential to reduce risk of hazards and increase the speed of recovery for coastal and inland watersheds.

\section{Products}

The primary product is technical report that provides a resilience definition that meets a set of requirements with clear relationships to metrics of the relevant abstract notions of reliability and risk. The report also provides metrics that are practical and simplified while capturing all the attribute set in the resilience definition. Recovery models with case studies, and illustrative examples are also provided. Next steps are defined. The report contributes towards advancing the USACE's capabilities in defining, quantifying, and assessing coastal and watershed

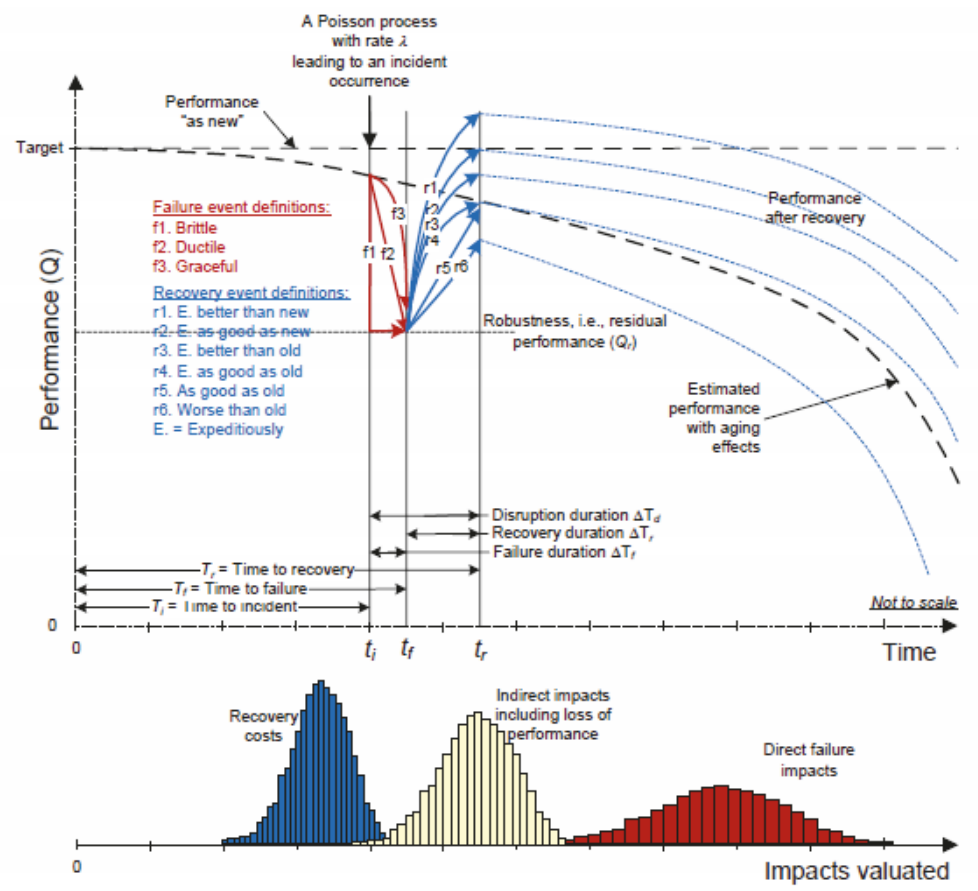
system resilience. The effort results include example applications on how to measure performance of coastal infrastructure, illustrations on relating performance to resilience, per Figure 1, and illustrative computational examples of resilience including suggested recovery profiles. 


\section{Problem}

This work unit is directed towards developing a framework to compare resilience of engineered features (e.g.: sea wall, near shore berm, levee, etc.) with resilience of natural and nature based features (NNBF) that are created by the beneficial use of dredged sediment or a combination of dredged sediment and engineered features (e.g.: salt marsh with sea wall).

\section{Approach}

USACE District scientists and engineers need a systematic approach to evaluate resilience of various alternatives, including resilience of coastal systems from natural and nature-based features (NNBF). Research has advanced the understanding of: Flood Risk Management (FRM) benefits from wave-energy dissipation through wetlands; Navigation benefits by analysis of the dredged material life cycle; and other benefits, such as ecosystem services. However, each of these areas affirm a need to better understand the natural physical system as well as identify prospective demonstration projects - both require a systematic framework and performance metrics to measure resilience. This work attempts to address those goals by creating a framework for projects that are created with the beneficial use of dredged material.

\section{Products}

The products are: (1) a framework to evaluate FRM benefits, Navigation benefits, and other direct and incidental benefits (i.e.: Ecosystem Services); (2) performance metrics to quantify resilience; and (3) a case study to evaluate benefits of a NNBF which is created, or enhanced, from the beneficial use of dredged sediment (e.g.: salt-marsh).

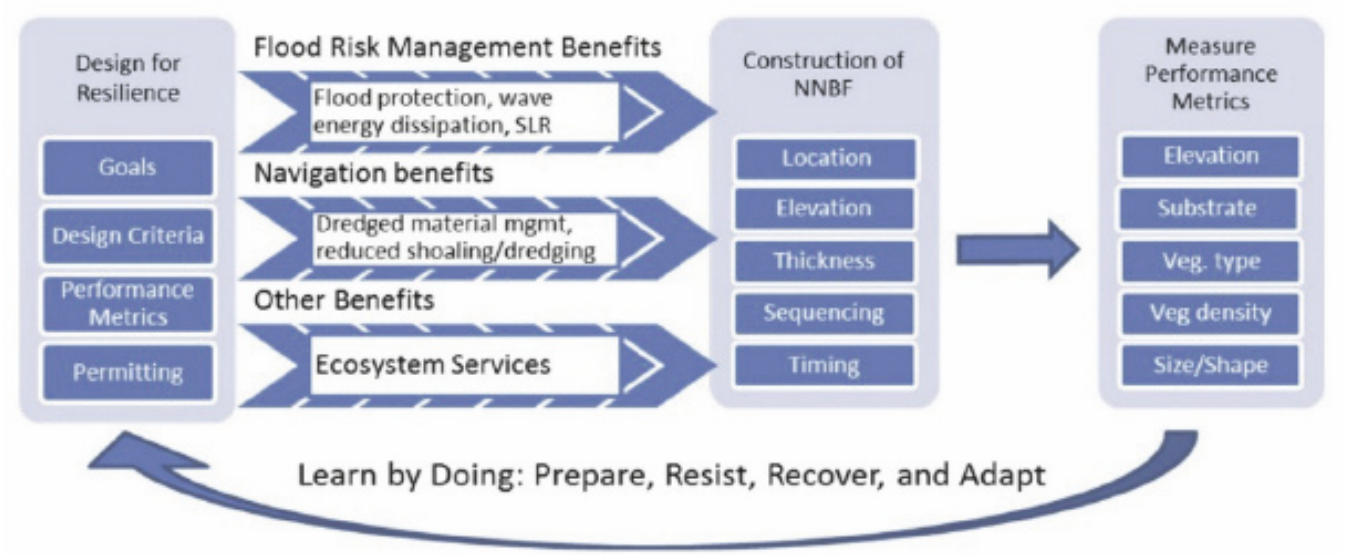

NNBF Framework to measure performance metrics and quantify resilience

Identification of performance metrics will allow Districts to design, construct, and measure NNBF. Beginning with FRM benefits, the Coastal System Resilience Program will quantify resilience using existing methods, including numerical modeling to analyze wave-energy dissipation with/without NNBF. This framework will provide the technical basis for sound engineering to quantify, predict and manage risk reduction and increased resilience for coastal infrastructure.

POC: John Childs, Environmental Laboratory

Katherine Touzinsky, Coastal and Hydraulics La-

John.L.Childs@usace.army.mil boratory 


\section{Appendix B: Research Supporting the Multi- Project and Community Scales}

Coastal Foredune Accretion and Erosion Monitoring and Modeling ...

An Integrated Approach to Dune Morphology Modeling under Ecosystem

Management and Restoration Research Program ................................................. B-2

Metrics for Evaluating Coastal Vegetation Features Contribution to Resilience Using Historical Imagery ............................................................................................... B-3

Dune and Beach Resilience Metrics under Navigation Systems............................ B-4 


\section{Coastal Foredune Accretion and Erosion Monitoring and Modeling}

\section{Problem}

This research will aim to understand and predict the resiliency of our Nation's coasts, with a focus on managing beaches and dunes adjacent to coastal inlets. Coastal foredunes are dynamic features that are eroded by large waves during storms and built by Aeolian transport. Dunes act as a natural buffer, protecting the land behind them from all but the largest of storms, and so have gained recent attention as nature-based infrastructure (NBI) that the Corps can exploit to increase coastal resiliency and protection during storms. For example, during Hurricane Sandy, communities that had invested in coastal foredunes suffered less damage than communities which lacked a foredune. Specifically, the USACE is interested in maximizing the effect of dredged sand from coastal inlets that is placed on the shoreline to build a resilient coastline. In order to accurately address these questions, more research is needed to (1) develop a predictive model of dune evolution that includes both dune erosion and growth variables, and (2) use that model to help identify the most important variables for designing resilient coastal systems.

\section{Approach}

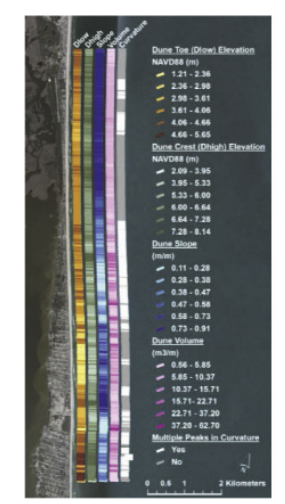

Dune feature-

extraction code

Previous dune-based research has (1) developed a conceptual model of coastal foredune dynamics based on literature review; (2) identified links between foredune morphology and foredune state, and (3) collected detailed data at the Field Research Facility (FRF) in Duck, NC observing a one-year cycle of dune evolution on a prograding and eroding dune field. These prior efforts are being leveraged in the development of a probabilistic model which couples hydrodynamic forcing and dune growth variables to parameterize factors affecting dune erosion by storm waves and the efficiency of aeolian transport and sand trapping at the dune base. Once built, this model will be trained on the unique record of wind, waves, and topography collected at the Field Research Facility (FRF) in Duck, NC and used to hindcast 30-years of dune evolution in order to identify which variables are the most important for encouraging resilience during periods of dune growth and erosion.

\section{Products}

The products for this effort are 1) A Technical Report: Swann, C., Brodie, K., Spore, N. 2015. Coastal Foredunes: Identifying Coastal, Aeolian, and Management Interactions Driving Morphologic State Change. TR-15-17 and 2) Feature extraction code: delineates dune toe, dune crest, dune slope, volume and curvature along each shore normal transect, 3) monthly high-resolution lidar surveys of healthy, scarped, and anthropogenically influenced dune sites; and 4) probabilistic modeling tool for predicting dune growth and erosion suitable for end user use (in development). The results of this research will help quantify which environmental factors (Grain size, wind climatology, fetch, dune morphology, beach morphology, vegetation, wave climate) are the most important for predicting dune growth and erosion, identifying optimal design parameters for resilient beach-dune systems. High-resolution observations of dune volume change on a natural eroding, a natural prograding, and a human-influenced dune field will help identify differences between processes driving dune evolution on natural and developed coastlines. More information available here: http://cirp.usace.army.mil/pubs/techreports.php

POC: Kate Brodie, CHL Field Research Facility (FRF)

Nick Spore, FRF

Meg Palmsten, FRF
Katherine.L.Brodie@usace.army.mil Nicholas.J.Spore@usace.army.mil Meg.Palmsten@nrlssc.navy.mil 


\section{An Integrated Approach to Dune Morphology ing under the Ecosystem Management Restoration Research Program}

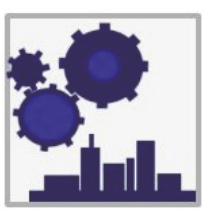

\section{Problem}

This work unit is directed towards improving coastal morphology modeling by integrating recovery processes mediated by vegetation. The integrated model will employ a probabilistic life-cycle approach to modeling dunes and other coastal barriers. The model utilizes a process-based approach to quantify the effects of vegetation on dune response to storms and natural dune recovery between storms. This will allow for better management and planning of coastal dune systems for multiple benefits such as critical habitat or storm damage reduction.

\section{Approach}

Barrier islands and other barrier features such as spits and dunes shelter coastlines from storm damage and protect fragile wetland ecosystems that occupy landward edges of such features. They are critical components of an integrated coastal system and a valuable example of natural and nature-based features. Sea level rise and climate change threaten to alter or irreparably damage the physical and ecological structure and function of barrier island and dune systems. Barrier island evolution is complex, integrating multiple physical and ecological processes and our current tool set cannot account for these complex interactions, especially under uncertain future conditions. Fully integrating physical and ecological process based models will capture the complex interactions controlling dune and barrier island evolution and allow us to better predict future conditions using a lifecycle approach. This work unit will help scientists, engineers, and coastal managers understand the impact of dune vegetation on dune morphology, what role vegetation may play during minor to intermediate storm events, and how dunes may recover between storm events marking an advance in understanding of dune response and recovery over a project lifetime.

\section{Products}

The primary product expected from this effort is a framework that can project the response of dune and barrier island systems to disturbances such as storms and changing environmental conditions such as sea level rise and climate change. The two-tiered modeling framework can be used to compare project alternatives and quantify benefits using a probabilistic approach. The tiered approach is designed to best suit USACE District and Division needs. In its simplest form (Tier 1), it can be used as a screening tool for

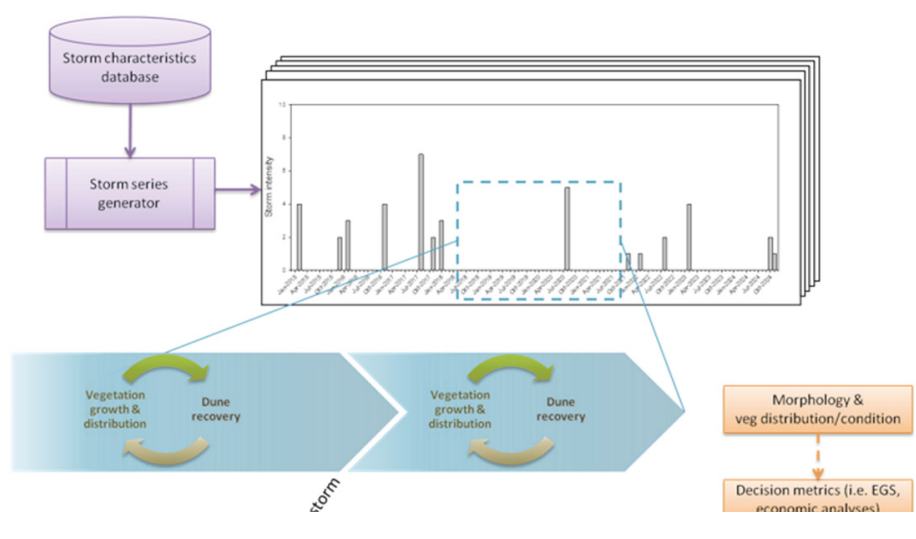

Tier 2 model schematic SMART Planning. More moderate levels of complexity (Tier 2) can be implemented for quantitative alternative comparison and analysis of the full 50 -year project lifecycle. Outputs will include a temporally and spatially explicit projection of possible future dune morphology and vegetation condition and distribution that can be used to calculate decision metrics such as ecological benefits and ecosystem goods and services. The integrated morphology model will be applied for validation and demonstration purposes at Onslow Beach on Marine Corps Base Camp Lejeune, NC and at the ERDC Field Research Facility in Duck, NC. The vegetation portion of the model will be tested at Assateague Island National Seashore, MD. 


\section{"Ir." Metrics for Evaluating Coastal Vegetation Features Contribution to Resilience using Historical Imagery}

\section{Problem}

The Metrics for Evaluating Coastal Vegetation Features work unit is directed towards improving the understanding of how vegetated coastal features protect coastlines and structures from storm damage and/or aid in recovery of the coastline. The investigation will be carried out using coastal imagery from before and after storm events in locations where natural experiments of such features have occurred.

\section{Approach}

USACE District scientists and engineers need have been encouraged to consider natural and nature-based features in the planning of comprehensive coastal protection projects. Although laboratory-scale studies indicate that sub-aerial and subaqueous vegetation have the potential to attenuate wave energy and act as storm water retention basins, it remains to be seen whether the implementation and configuration of these features at full scale in nature produce the desired effect. The results of the project will substantially improve the USACE district planners' abilities to assess the importance and effectiveness of natural or engineered nature-based features in reducing damage risk reduction. As a direct effect, planning managers should be able to more confidently quantify the monetary and non-monetary benefits of comprehensive projects, reducing the development cycle timeline.

\section{Products}

The primary product is a white paper describing metrics that can be obtained from aerial photographs to assess the performance of vegetated features on coastlines before and after storm events. The report will include a literature review of similar (in any) studies performed in Europe or other international locations. The results of the metric analysis at the chosen case study site will also be presented. The initial project phase is aimed at identifying relevant and attainable metrics. A case study location will be chosen from among critical coastlines, with potential sites in Mobile Bay, AL or Rockaway, NY. Applications will depend on the availability of data, including that from the USACE JABLTEX program, NOAA Coastline Mapping Project, USGS Coastal Change Hazards Program, and the Army National Geospatial-Intelligence Agency. Future phases of the project may include analysis of different type of vegetated coastal features at multiple sites along the Gulf and East Coast of the United States. 


\section{Dune \& Beach Metrics under Navigation Systems}

\section{Problem}

The Dune \& Beach Resilience Metrics work unit is directed towards improving basic understanding of coastal system resilience associated with the Corps' dune and beach nourishment projects for coastal storm risk management (CSRM) purposes.

\section{Approach}

Quantifing resilience in a consistent manner will allow USACE District scientists and engineers to make decisions about how dune and beach nourishment projects are implemented. For this effort resilience will be defined as the ability of a system to anticipate, resist, recover, and adapt to achieve functional performance

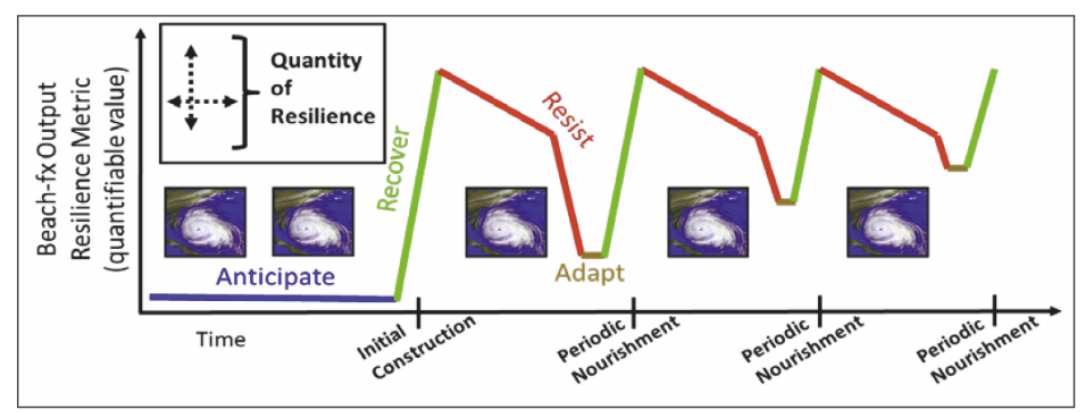

Resilience timeline specific to CSRM Dune and Beach Nourishment Projects under the stress of disturbances through time. Specific and quantifiable data can be used to describe the functionality of a project. Time series data describing the functionality of a project can be used to quantify resilience. A key finding of the NACCS (North Atlantic Coast Comprehensive Study, January 2015) is that resilience can be encouraged through the use of a coastal storm risk management framework, however there is not a clear way to quantify resilience for CSRM dune \& beach nourishment projects. ERDC SR-15-1 (Use of Natural and Nature-Based Features (NNBF) for Coastal Resilience, January 2015), presents framework for analyzing the contribution of NNBF, such as dune \& beach nourishment, to coastal system resilience. This report states that, "Models, tools and techniques to assess coastal systems, such as Beach-fx... can be applied to quantify performance..." Beach-fx is the Corps certified model used to evaluate and analyze the benefits and costs of dune and beach nourishment projects. It is a life-cycle simulation model that produces time series output data describing the physical coastal morphology and the economic performance of the project. This modeled data, describing how the dune and beach system function over time, will be used to quantify resilience of the project.

\section{Products}

Task 1 (FY16): Develop a more specific understanding of how the definition of resilience applies to CSRM dune \& beach nourishment projects, and specific metrics for quantifying resilience using Beach- $\mathrm{fx}$ model results. These benefits will be for the entire USACE coastal community of practice. The report produced for Task 1 would be disseminated to the USACE Coastal Working Group (CWG) and the Regional Sediment Management Community. The findings from this analysis will be presented at monthly CWG and/or RSM bi-monthly webinars as well as at other appropriate webinars or conferences.

Task 2 (FY17): Develop a standard process for quantifying resilience that can be used USACE wide for any study using Beach-fx, which is currently the only Planning Center of Expertise approved model for determining the benefits of CSRM dune \& beach nourishment projects. A standard process will ensure that resilience is being considered equally for dune \& beach nourishment projects throughout USACE. Task 3 (FY17): Develop a clear direction on how the quantifiable resilience metrics should be used for CSRM dune \& beach nourishment project development across USACE.

POC: Marty Durkin, Regional Sediment Manage-

Martin.T.Durkin@usace.army.mil ment (RSM) Center of Expertise

Jackie Keiser \& Jason Engle, RSM Center of Expertise 


\section{Appendix C: Research Supporting the Regional and National Scales}

National Coastal Resilience Network ........................................................................ C-1

Measuring Climate Risk to Inform Resilience: A Pilot Study for North Atlantic Medium and High-Use Seaports ....................................................................................... C-2 


\section{National Coastal Resilience Network}

\section{Problem}

The National Coastal Resilience Network research topic aims to take the first step toward integrating several federal agency's coastal processes research and data collection efforts toward resilience into a coastal resilience network for local communities.

\section{Approach}

Since Hurricane Sandy, coastal resilience has become a national objective. Numerous federal agencies charged with studying and managing U.S. coasts are developing tools to help communities improve resilience. Improved resilience is often cited as a broader impact benefit of coastal processes research. Meanwhile, coastal planners, local elected officials and decision makers in coastal communities are being inundated with different definitions of resilience

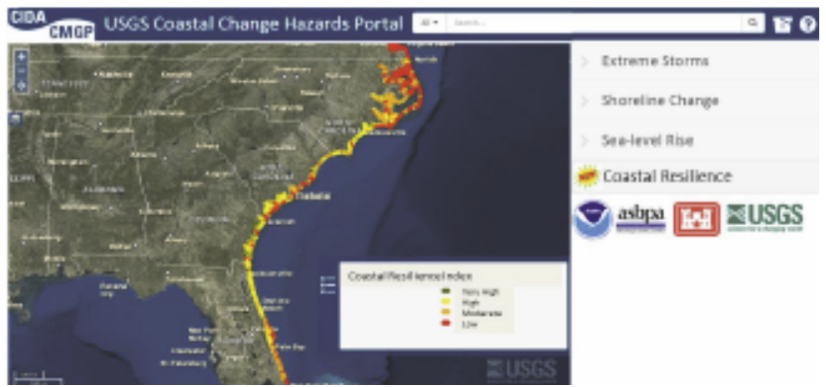

Mock-up of the new Coastal Resilience tab on the nationalscale USGS Coastal Change Hazards Portal. and various tools to improve their resilience. To date, our nation lacks a national coastal resilience plan. Multiple agencies are contributing valuable science toward resilience, and as such, an opportunity exists to identify efficiencies at the federal level while engaging and assisting local communities. This approach utilizes a scenario methodology that unites the predictive and dynamic capabilities of simulation models through pre-determined coastal management strategies that depend on policy, community, and property owner values. It is a life-cycle analysis that combines an infrastructure analysis with environmental and social decision-making factors. A spatially-explicit, policy-centric modeling framework, is modified to examine interactions between human and natural systems across a landscape.

\section{Products}

The key product from this research is a GIS-based tool to analyze coastal system resilience by linking federal databases through empirical and analytical relationships, numerical models, and management/ policy scenarios. The approach integrates research goals and objectives across and within federal agencies (e.g., in different mission areas and departments (planning, design, operations, etc.) of the USACE) and will facilitate selection of user/ customer-based priorities and provide systematic approaches that are scalable (project-community-region), defensible, and transparent. For example, project managers can assess the resilience scenarios at any point in the infrastructure project life cycle, to determine coastal resilience at that time (e.g., is the community ready for a coastal hazard?). The effort is a multi-agency collaboration led by the American Shore and Beach Preservation Association (ASBPA) leveraging available data from the USGS, the U.S. Army Corps of Engineers (USACE), and NOAA. The USGS Coastal Change Hazards Portal, an existing web-based platform displaying a national map, will be expanded with the addition of a Coastal Resilience tab (see figure). The methodology includes various predetermined policy scenarios for different sections of coast based on the existing community management strategies. The various management strategies are evaluated using a suite of landscape metrics to determine the future community resilience under existing management strategies. These types of analysis scenarios will benefit coastal planners in determining the feasibility and value of future and ongoing coastal projects.

POC: Nicole Elko, American Shore and Beach

Nicole.Elko@asbpa.org

Preservation Association

Hillary Stockdon, US Geological Survey

hstockdon@usgs.gov 


\section{Measuring Climate Risk to Inform Resilience: A Pilot Study for North Atlantic Medium and High-Use Ports}

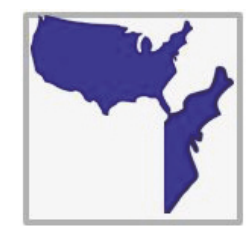

\section{Problem}

In collaboration with the United States Army Corps of Engineers (USACE), University of Rhode Island researchers are developing a climate risk indexing tool that will contribute to a deeper understanding of emerging challenges that are a result of future climate change.

\section{Approach}

On a national and regional scale, evaluation of port-related investment proposals, including dredging and coastal protection, requires an understanding of how storm events at maritime freight nodes (i.e., coastal ports) impact both the greater economy and ecosystems in which ports reside and the level of resilience inherent to a port system. Higher incidence of natural disasters due to climate change will result in more disruption for communities, ecosystems, and economies of trading partners both domestically and internationally.

\section{Products}

This pilot project will select, weight, and aggregate indicators of climate risk across the 23 high and mediumuse coastal ports in the USACE North Atlantic Districts coastal inlets and navigation channels. The project will convene an expert group of 12-15 members representing the perspectives of various transportation system representatives who will discuss the concept of seaport climate risk and resilience and find consensus around the following concepts:

- How do various climate risks relate to "resilience" as defined for coastal port systems?

- What datasets should be considered in order to measure aspects of climate risk?

- What measurable indicators of climate risks are common across US North Atlantic coastal ports?

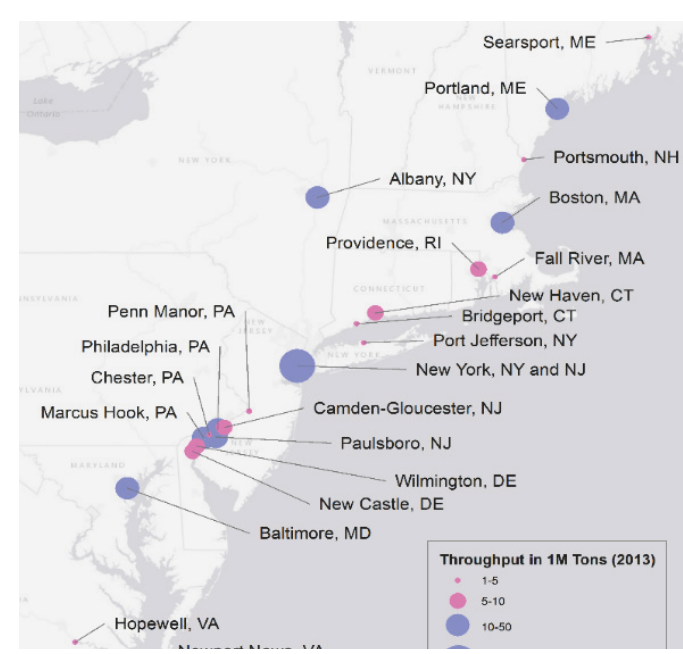

North Atlantic Medium (pink) and High-Use (purple) ports (2013)

The resulting decision-support tool will inform decision-makers in the USACE and other agencies as they consider priorities with respect to enhancing resilience of port infrastructure to protect both the ecosystems in which ports are located and the socio-economic systems which depend on port operations. Through this work, regional and national decision makers will gain a tool to better understand the resilience of the system of ports for which increased resilience may translate into shipping cost savings through reduced down time.

POC: Dr. Austin Becker, University of Rhode Island

abecker@uri.edu (URI) mcintosh@my.uri.edu Duncan McIntosh, URI

Katherine Touzinsky, Coastal and Hydraulics Laboratory 


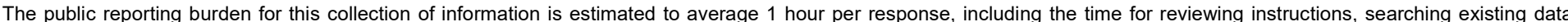

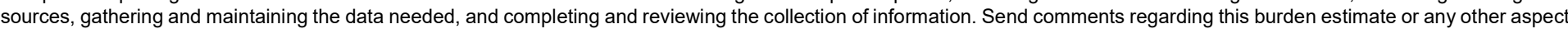

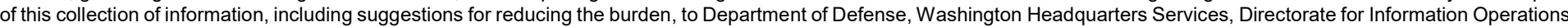

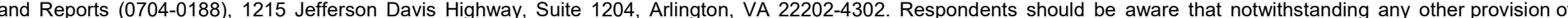
law, no person shall be subject to any penalty for failing to comply with a collection of information if it does not display a currently valid OMB control number.

PLEASE DO NOT RETURN YOUR FORM TO THE ABOVE ADDRESS.

\begin{tabular}{l|l|l}
\hline $\begin{array}{l}\text { 1. REPORT DATE } \\
\text { December } 2018\end{array}$ & $\begin{array}{l}\text { 2. REPORT TYPE } \\
\text { Final Report }\end{array}$ & 3. DATES COVERED (From - To) \\
\hline
\end{tabular}

\section{TITLE AND SUBTITLE}

USACE-ERDC Coastal System Resilience Research 5a. CONTRACT NUMBER

5b. GRANT NUMBER

5c. PROGRAM ELEMENT NUMBER

5d. PROJECT NUMBER

462579

Katherine F. Touzinsky and Julie D. Rosati 5e. TASK NUMBER

5f. WORK UNIT NUMBER

8. PERFORMING ORGANIZATION REPORT NUMBER

ERDC/CHL SR-18-4 USACE

U.S. Army Corps of Engineers

Washington, DC 20314-1000

11. SPONSOR/MONITOR'S REPORT NUMBER(S)

\section{DISTRIBUTION/AVAILABILITY STATEMENT}

Approved for public release; distribution is unlimited.

\section{SUPPLEMENTARY NOTES}

\section{ABSTRACT}

Coastal systems are complex and diverse landscapes that provide significant navigation, flood risk management, and ecosystem services to communities. However, they are influenced by episodic and long-term change from environmental and human-related constraints and hazards. The Coastal Systems Resilience (CSR) initiative integrates three separate but parallel research, development, and technology (RD\&T) programs (Environmental Restoration, Navigation, and Flood Risk Management) within the U.S. Army Engineer Research and Development Center to address resiliency of this dynamic region. The initiative utilizes new and existing science and engineering to define metrics and to create tools to quantify coastal system resilience of existing and proposed civil works activities. This special report describes the motivation and vision for coastal resilience research that was initiated in Fiscal Year 2016 under the CSR RD\&T programs and provides a summary of work to date.

\section{SUBJECT TERMS}

Coastal engineering, Flood control, Natural disasters, Resilience (Ecology)

\section{SECURITY CLASSIFICATION OF:}

\begin{tabular}{l|l|l|}
\hline a. REPORT & b. ABSTRACT & c. THIS PAGE \\
Unclassified & Unclassified & Unclassified
\end{tabular}

17. LIMITATION OF
ABSTRACT
SAR

\section{NUMBER OF 19a. NAME OF RESPONSIBLE PERSON PAGES}

39

\author{
Katherine F. Touzinsky \\ 19b. TELEPHONE NUMBER (Include area code) \\ 202-761-7582
}

